\title{
Full scale field testing of trapezoidal core sandwich panels subjected to adjacent and contact detonations
}

\author{
H. Al-Rifaie, R. Studziński, T. Gajewski, M. Malendowski, P. Peksa, W. Sumelka \& \\ P.W. Sielicki \\ Faculty of Civil Engineering and Transport, Poznań University of Technology, Poznań, Poland
}

\begin{abstract}
Corrugated-core sandwich panels are efficient protective structures that can absorb blast/impact energy through plastic deformation. A relatively non-expensive folding technique is used to manufacture the core to different topologies. Literature survey revealed that the dynamic response of metallic trapezoidal corrugated-core sandwich panels subjected to near-field/contact detonations has not yet been thoroughly investigated. Hence, the aim of this study is to examine, with field tests, if trapezoidal core sandwich panels can protect a precast concrete target from adjacent/contact detonations. The performance and damage behavior of two pre-cast RC slabs were assessed with and without aluminum sandwich panels. The two slabs were subjected to 4 detonations ranging from close to contact explosions. The study concludes that the implemented sandwich panel is not suitable for near-field or contact detonations and might be a protective solution for far-field explosion scenarios.
\end{abstract}

\section{INTRODUCTION}

The need for more robust systems of protection is of vital importance due to this increasing risk of explosive attacks (Al-Rifaie and Sumelka, 2017). Exposure of civilian facilities to explosion scenarios cannot be entirely avoided, but the effects of such accidents can be greatly mitigated by the use of protective systems, such as sandwich panels. To absorb the energy from blast/shock/impact, sandwich panels are used as sacrificial structures. They are usually made up of an inner-core sandwiched between two plates. The inner-core can be classified as either cellular or corrugated. The blast energy dissipation of such panels is based on the plastic deformation of the core.

Cellular cores can be metallic foams (Nowak et al., 2017), honeycomb structures (Li et al., 2014) or auxetic topologies (Al-Rifaie and Sumelka, 2019, Al-Rifaie and Sumelka, 2020) that are efficient but relatively expensive to produce (3D-printing). This may restrict their uses to particular fields, such as the aerospace field, biomedical engineering and military equipment. Corrugated core sandwich panels have been suggested as an alternative due to their high longitudinal stretching, shear strength and energy absorption properties (Zhang et al., 2015, Wiernicki et al., 1991). To manufacture the corrugated layers, a relatively non-expensive folding technique is used. The geometric topologies can be triangular, sinusoidal, rectangular or trapezoidal-shaped (Al-Rifaie et al., 2021). The later proved its performance compared to other topologies (Rong et al., 2018).

The performance of sandwich panels (with trapezoidal core) subjected to far-field explosions was generally perceived by researchers, either numerically or through real field testing. However, according to the authors' survey, the dynamic response of metallic trapezoidal corrugated-core sandwich panels subjected to near-field/contact detonations has not yet been thoroughly investigated. Hence, the aim of this study is to investigate, with field tests, if

DOI: $10.1201 / 9781003132134-50$ 
trapezoidal-core sandwich panels can protect a pre-cast concrete target from adjacent/contact detonations.

\section{CASE STUDY}

\subsection{Sandwich panel properties}

The panel used in this research is composed of 8 trapezoidal corrugated layers manufactured using cold-form press technique. The directions of the corrugated layers is cross-arranged $\left(0^{\circ} / 90^{\circ}\right)$, as better energy absorption can be achieved compared to the regular-arranged (AlRifaie et al., 2021). The 8 aluminum layers are neither welded, nor bolted together. They are hold by a C-shaped aluminum frame. The layer itself has a thickness of $1.5 \mathrm{~mm}$ while the frame has $2 \mathrm{~mm}$. Figure 1 shows the geometrical properties of the aluminum sandwich panel and its trapezoidal corrugated core. The sandwich panel has exterior dimensions of $1000 \times 1000 \times 163 \mathrm{~mm}$. Two sandwich panels of this type were used in this research. The aluminum material properties are listed in Table 1.

\subsection{The RC slab}

As mentioned earlier, the sandwich panels are supposed to protect a concrete target from contact or adjacent detonations. Two 3000x1500x145 mm pre-cast RC slabs were used. Each slab is simply supported on 2 concrete supports. The slab is reinforced with upper and lower layers of similar reinforcement. Each layer has longitudinal main reinforcement of $\emptyset 10 \mathrm{~mm} @ 150 \mathrm{~mm} c / c$

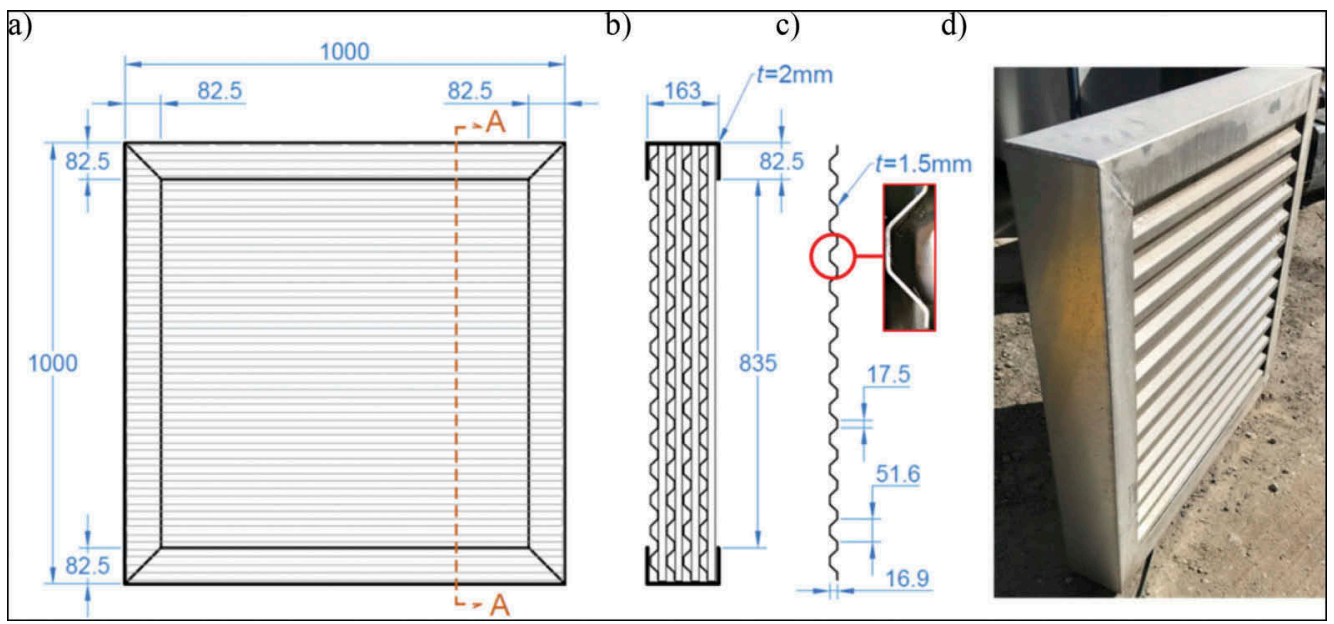

Figure 1. Geometrical properties of the aluminum sandwich panel and its trapezoidal corrugated core where: a) Top view, b) Section A-A, c) One layer and d) Produced panel.

Table 1. Material properties of the aluminum, reinforcing steel and concrete used in this study.

\begin{tabular}{|c|c|c|c|c|c|c|}
\hline \multirow[b]{2}{*}{ Material } & \multirow[b]{2}{*}{ Grade } & \multirow{2}{*}{$\frac{\text { Young's Modulus }}{\mathrm{GPa}}$} & \multirow{2}{*}{$\begin{array}{l}\text { Poisson's Ratio } \\
-\end{array}$} & \multicolumn{2}{|l|}{ Strength } & \multirow{2}{*}{$\frac{\text { Density } \rho}{\mathrm{kg} / \mathrm{m}^{3}}$} \\
\hline & & & & $\mathrm{MPa}$ & & \\
\hline Aluminum & 6063-T5 & 70 & 0.3 & $F_{y}=130$ & $F_{u}=175$ & 2700 \\
\hline Steel reinforcement & B500A & 200 & 0.3 & $\mathrm{~F}_{\mathrm{y}}=500$ & $F_{u}=650$ & 7850 \\
\hline Concrete & C35/45 & 34 & 0.17 & $\mathrm{~F}_{\mathrm{cu}}=35$ & $F_{t}=3.2$ & 2430 \\
\hline
\end{tabular}




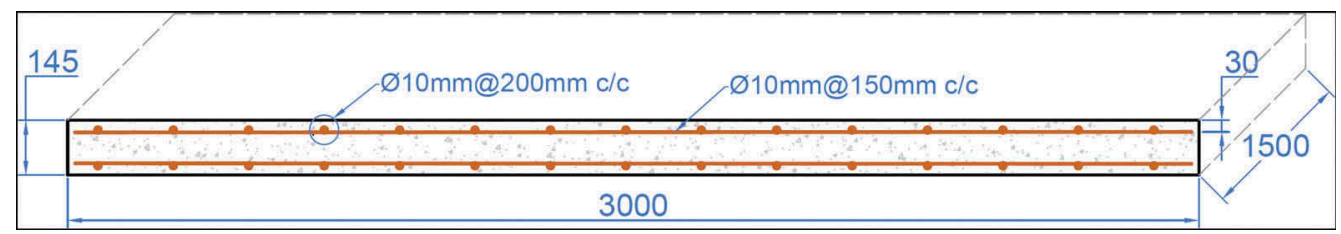

Figure 2. The reinforced concrete slab with its reinforcement details.

and transverse reinforcement of $\emptyset 10 \mathrm{~mm} @ 200 \mathrm{~mm} c / c$, as shown in Figure 2. The material properties for the concrete and the reinforcements are listed in Table 1. The test scheme and loadings are discussed in details in the flowing sections.

\subsection{Experimental setup}

The sandwich panels are supposed to protect the concrete slab from contact or adjacent detonations. To see the difference, two detonations $\left(1^{\text {st }}\right.$ and $\left.2^{\text {nd }}\right)$ were performed on a bare slab (Figures $3 \mathrm{a}$ and $3 \mathrm{~b})$. Then, two other similar detonations $\left(3^{\text {rd }}\right.$ and $\left.4^{\text {th }}\right)$ were conducted with the addition of the proposed sandwich panels (Figures $3 \mathrm{c}$ and $3 \mathrm{~d}$ ). The two pre-cast RC slabs were put on four concrete blocks/supports with $800 \times 800 \times 1600 \mathrm{~mm}$ each. The bearing area of the slab is $100 \times 1500 \mathrm{~mm}$ on each end, giving a clear slab span of $2800 \mathrm{~mm}$. The four detonations were done in sequence, one after the other with about an hour gap in between to analyze the performance and record the results. Each of the 4 detonations had mass of $1 \mathrm{~kg}$ of TNT and was positioned $750 \mathrm{~mm}$ far from adjacent slab edges. The stand-off distance for $1^{\text {st }}$ and $2^{\text {nd }}$ detonations (the distance between upper slab surface to the centroid of the explosive device) were $200 \mathrm{~mm}$ and $160 \mathrm{~mm}$, respectively (Figure 3b). The stand-off distance for the $3^{\text {rd }}$ and $4^{\text {th }}$ detonations were less, as sandwich panels were glued to the slab, leaving only $40 \mathrm{~mm}$ and $0 \mathrm{~mm}$, respectively. The $4^{\text {th }}$ detonation can be considered as a contact detonation attached directly to the sandwich panel's front layer.

The incident and peak reflected over-pressure generated from those 4 explosions, cannot be estimated using the well-known Kingery-Bulmash graphs/empirical equations. The reason is that they are close-range or contact blasts, where at this zone, more complex phenomena take

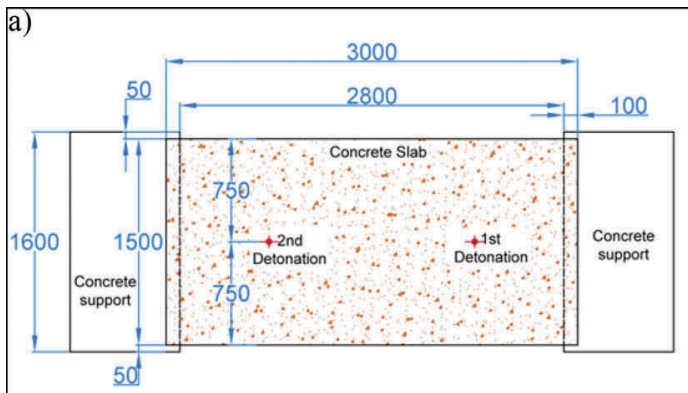

b)

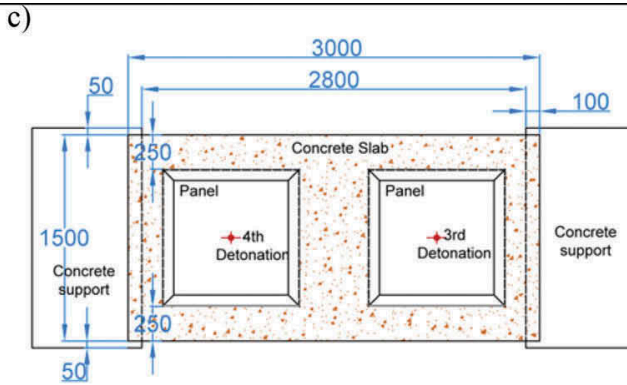

d)
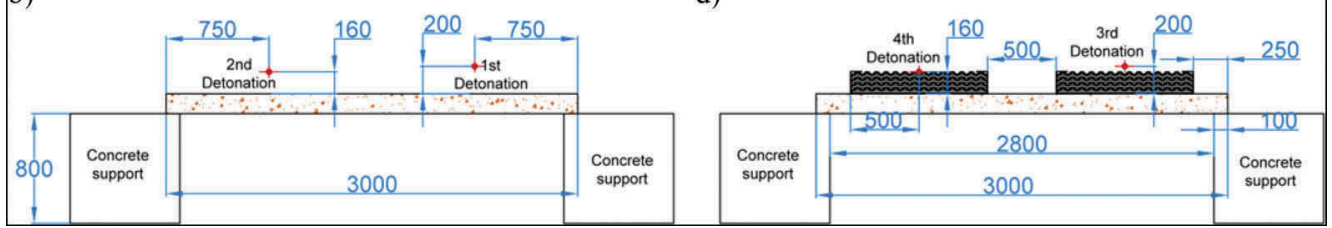

Figure 3. Field testing scheme with and without proposed sandwich panels. a) Top view-without panels, b) Side view-without panels, c) Top view-with panels and d) Side view-with panels. 
place due to afterburning and the violent outflow of the detonation gases (Novak et al., 2016). In other words, the pressure-time curve is not a single peak followed by exponential decay of Friedlander equation. There are limited test data available that might be used to validate the parameters for near regions (Baranowski et al., 2016, Bogosian and Heidenreich, 2012). Based on the mass of the TNT (W in $\mathrm{kg}$ ) and stand-off distance ( $\mathrm{R}$ in meters), the scaled distance $Z=(R) / \sqrt[3]{(W)}$ can be calculated as $0.2,0.16,0.04$ and $0 \mathrm{~m} / \mathrm{kg}^{1 / 3}$ for $1^{\text {st }}-4^{\text {th }}$ detonations, respectively. Those $Z$ values are less than the minimum scaled distance $0.4 \mathrm{~m} / \mathrm{kg}^{1 / 3}$ required to avoid close-range detonations (Rigby et al., 2015). Based on literature, the peak reflected over-pressure can roughly be estimated as $200,500,700$ and $900 \mathrm{MPa}$ for the $1^{\text {st }}-4^{\text {th }}$ detonation, respectively.

The $1 \mathrm{~kg}$ of TNT, refers to the situation when industrial infrastructural elements, such as gas cylinders, are located at a close distance from the structural elements. For example, in case of accidental explosion of $20 \mathrm{~L}$ of propane cylinder or $20 \mathrm{~L}$ of acetylene cylinder, they release blast energy equivalent to that of $0.82 \mathrm{~kg}$ and $0.86 \mathrm{~kg}$ of TNT, respectively (Studziński et al., 2021, Sielicki et al., 2017).

\section{RESULTS AND DISCUSSION}

\subsection{Behavior of RC slab without aluminum panels}

In general, the RC slab was able to resist the $1^{\text {st }}$ and $2^{\text {nd }}$ detonations without excessive damage. Figure 4 shows the behavior of the slab to the $1^{\text {st }}$ (Figures $4 \mathrm{a}$ and $4 \mathrm{~b}$ ) and $2^{\text {nd }}$ (Figures $4 \mathrm{c}$ and 4d) detonations. The upper surface, maintained its integrity, with minor erosion to its surface directly under the centroids of the explosive devices (Figures $4 \mathrm{a}$ and $4 \mathrm{c}$ ). The sides of the slab showed no visible cracks, although micro-cracks may exist. The bottom surface revealed concrete

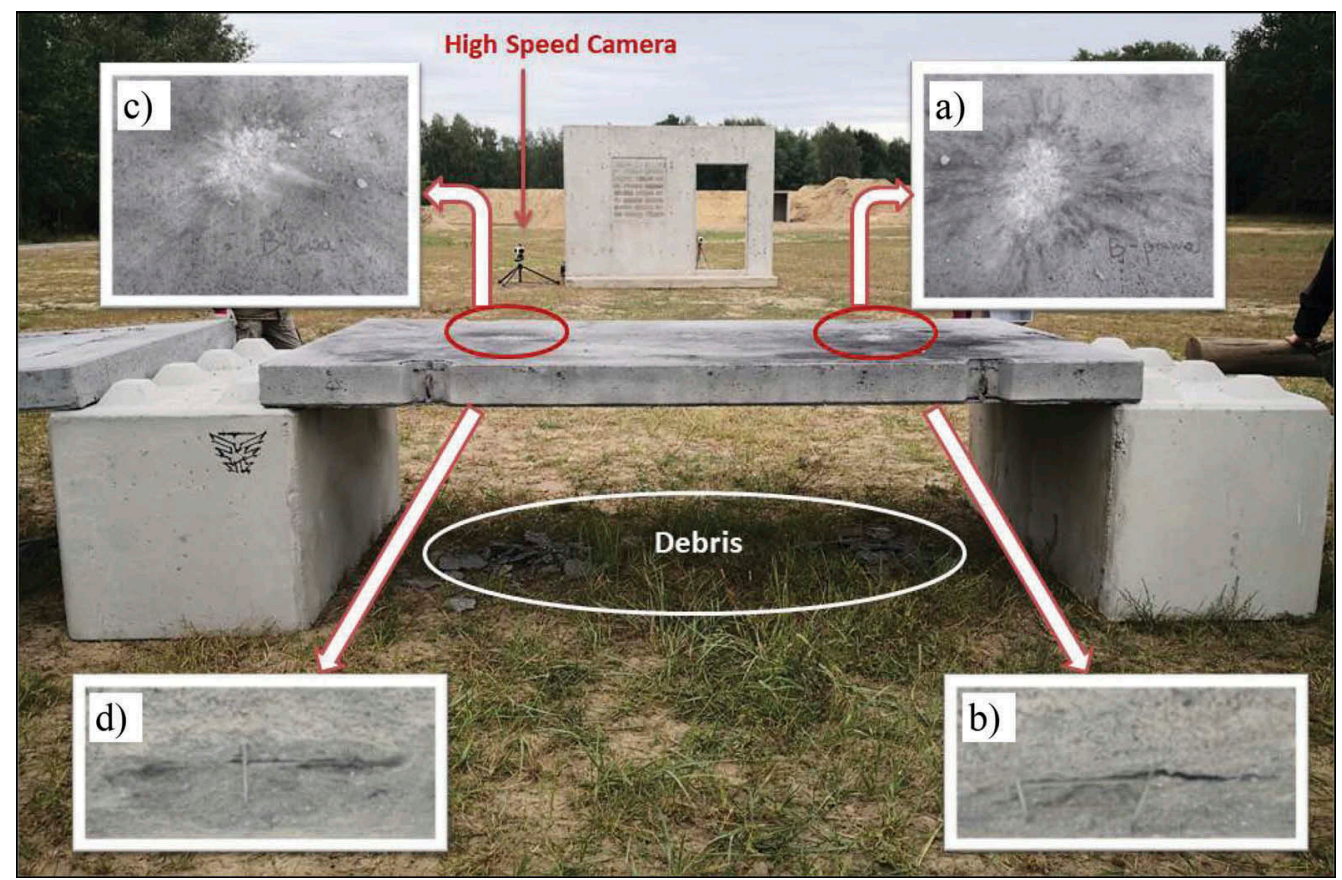

Figure 4. The failure mechanisms of the RC slab (without aluminum panels) subjected to 2 field detonations of $1 \mathrm{~kg}$ of TNT each, $1^{\text {st }}$ and $2^{\text {nd }}$, a) $1^{\text {st }}$ detonation, top concrete surface behavior, b) $1^{\text {st }}$ detonation, bottom concrete surface behavior, c) $2^{\text {nd }}$ detonation, top concrete surface behavior, d) $2^{\text {nd }}$ detonation, bottom concrete surface behavior. 
spalling and part of the reinforcement is visible (Figures $4 \mathrm{~b}$ and $4 \mathrm{~d}$ ). The mid-span deflection was recorded as $3 \mathrm{~mm}$. The aim of the addition of the sandwich panels in the next section is to see if the tension damage at the bottom surface of the slab would be reduced/prevented.

\subsection{Behavior of RC slab with the sacrificial aluminum panels}

Based on the testing scheme presented in Figures $3 \mathrm{c}$ and $3 \mathrm{~d}$, the two panels were glued to the top surface of the concrete (Figure 5a). When the $3^{\text {rd }}$ detonation was first performed, the panel (with mass of $45.2 \mathrm{~kg}$ ) was lifted and shifted $17.6 \mathrm{~m}$ away from the explosion location. The panel frame and the layers were also separated (Figure 5b). A circular local punching shear failure is the dominant behavior of the panel through all its 8 layers (Figures $5 \mathrm{c}-\mathrm{e}$ ). The adjacent panel, at this stage showed minor deformations due to the $3^{\text {rd }}$ detonation (Figure $5 b$ ). When the $4^{\text {th }}$ detonation was then performed, a similar panel behavior was observed, although the IED was in a complete contact with the frontal layer of the panel. These results agreed with (Kevin et al. (2013)) that contact detonations have extremely high pressures for just microseconds leading to local shear and punching failure.

The behavior of the concrete slab (with aluminum panels) is shown in Figure 6. The upper surface, under compression, was more deteriorated (Figures $6 \mathrm{a}$ and $6 \mathrm{c}$ ). The bottom surface (under tension) showed bigger areas of spalling with long visible longitudinal and transverse cracks (Figures $6 \mathrm{~b}$ and $6 \mathrm{~d}$ ). The sides of the RC slab were also cracked with visible damage (Figure 6e). The mid-span deflection was $73 \mathrm{~mm}$. It can be noticed that the addition of sandwich panels worsen the situation rather than protecting the slab. The cracks, damage and deflection were all more. The weight of the two panels $(\sim 90 \mathrm{~kg})$ and hence the kinetic energy from those panels might be the reason. Therefore, this study concludes that this type of sandwich panels may be protective in far-field explosion scenarios, but not for close or contact detonations.
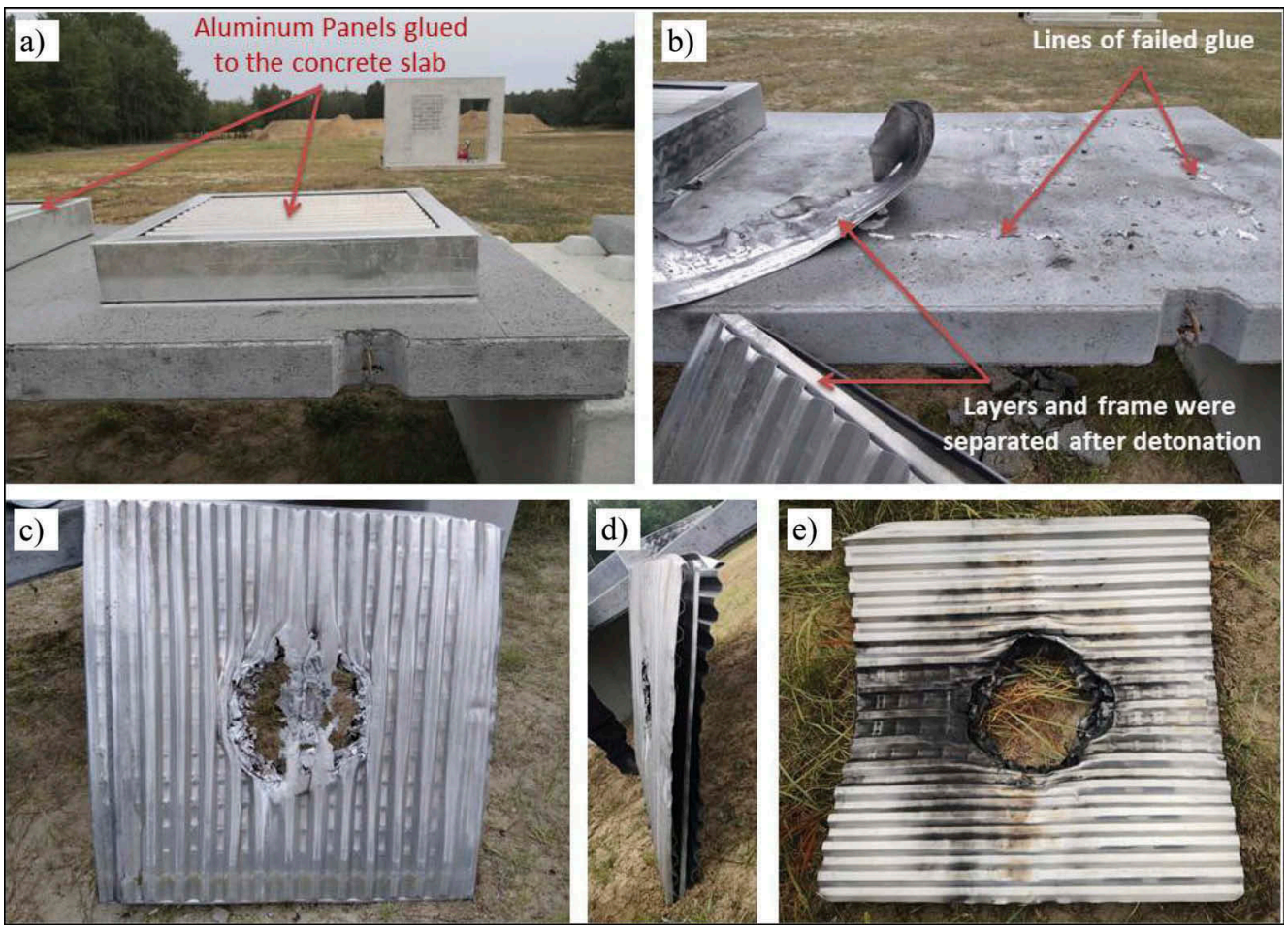

Figure 5. The failure modes of the aluminum panel after $3^{\text {rd }}$ detonation. 


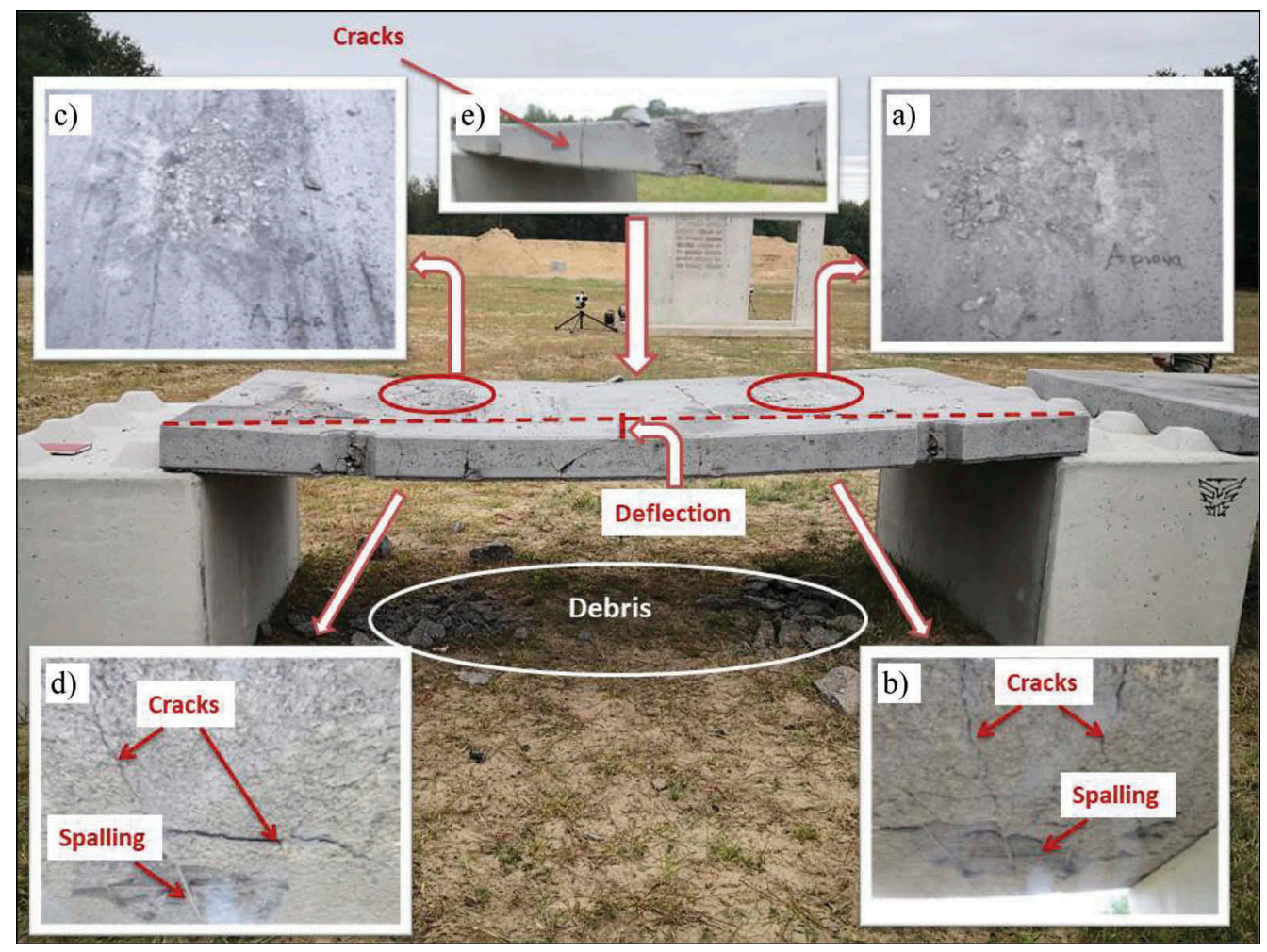

Figure 6. The failure mechanisms of the RC slab (with aluminum panel) subjected to 2 field detonations of $1 \mathrm{~kg}$ of TNT each. a) $3^{\text {rd }}$ detonation, top concrete surface behavior, b) $3^{\text {rd }}$ detonation, bottom concrete surface behavior, c) $4^{\text {th }}$ detonation, top concrete surface behavior, d) $4^{\text {th }}$ detonation, bottom concrete surface behavior, e) Side view of the concrete slab showing cracks and damage.

\section{CONCLUSIONS}

In this study, the performance and damage behavior of two pre-cast RC slabs were experimentally assesses with and without aluminum trapezoidal-core sandwich panels. The two slabs were subjected to 4 detonations ranging from close to contact explosions. Results showed that the behavior of the slabs was worse with the addition of those panels. More tension damage/ cracks were observed. The study concludes that this type of sandwich panels cannot resist close or contact detonations and might be a protective solution for far-field explosion incidents.

\section{ACKNOWLEDGEMENT}

This work was supported by the National Centre for Research and Development, Poland, grant DOB-BIO10/01/02/2019 within Defence and Security Programme.

\section{REFERENCES}

Al-Rifaie, H., Studziński, R., Gajewski, T., Malendowski, M., Sumelka, W. \& Sielicki, P. W. 2021. A New Blast Absorbing Sandwich Panel with Unconnected Corrugated Layers-Numerical Study. Energies, 14, 214.

Al-Rifaie, H. \& Sumelka, W. 2017. Numerical analysis of reaction forces in blast resistant gates. Structural Engineering and Mechanics, 63, 347-359. 
Al-Rifaie, H. \& Sumelka, W. 2019. The developement of a new shock absorbing Uniaxial Graded Auxetic Damper (UGAD). Materials, 12, 2573.

Al-Rifaie, H. \& Sumelka, W. 2020. Improving the Blast Resistance of Large Steel Gates-Numerical Study. Materials, 13, 2121.

Baranowski, P., Malachowski, J. \& Mazurkiewicz, L. 2016. Numerical and experimental testing of vehicle tyre under impulse loading conditions. International Journal of Mechanical Sciences, 106, 346-356.

Bogosian, D. \& Heidenreich, A. An evaluation of engineering methods for predicting close-in air blast. Structures congress, 2012. 90-101.

Kevin, C., Van Doormaal, A., Haberacker, C., Hüsken, G., Larcher, M., Saarenheimo, A., Solomos, G., Stolz, A., Thamie, L. \& Valsamos, G. 2013. Resistance of structures to explosion effects. Review report of testing methods, Ispra: European Commission-Joint Research Centre.

Li, X., Zhang, P., Wang, Z., Wu, G. \& Zhao, L. 2014. Dynamic behavior of aluminum honeycomb sandwich panels under air blast: Experiment and numerical analysis. Composite Structures, 108, 1001-1008.

Novak, N., Vesenjak, M. \& Ren, Z. 2016. Auxetic cellular materials-a review. Strojniški vestnik-Journal of Mechanical Engineering, 62, 485-493.

Nowak, Z., Nowak, M., Pecherski, R., Potoczek, M. \& Sliwa, R. 2017. Numerical simulations of mechanical properties of alumina foams based on computed tomography. Coupled Field Problems and Multiphase Materials, 107.

Rigby, S. E., Tyas, A., Clarke, S. D., Fay, S. D., Reay, J. J., Warren, J. A., Gant, M. \& Elgy, I. 2015. Observations from preliminary experiments on spatial and temporal pressure measurements from near-field free air explosions. International Journal of Protective Structures, 6, 175-190.

Rong, Y., Liu, J., Luo, W. \& He, W. 2018. Effects of geometric configurations of corrugated cores on the local impact and planar compression of sandwich panels. Composites Part B: Engineering, 152, 324-335.

Sielicki, P., ŁodygowskI, T., Al-Rifaie, H. \& Sumelka, W. 2017. Designing of Blast Resistant Lightweight Elevation System-Numerical Study. Procedia Engineering, 172, 991-998.

Studziński, R., Gajewski, T., Malendowski, M., Sumelka, W., Al-Rifaie, H., Peksa, P. \& Sielicki, P. W. 2021. Blast Test and Failure Mechanisms of Soft-Core Sandwich Panels for Storage Halls Applications. Materials, 14, 70.

Wiernicki, C. J., Liem, F., Woods, G. D. \& Furio, A. J. 1991. Structural analysis methods for lightweight metallic corrugated core sandwich panels subjected to blast loads. Naval Engineers Journal, 103, 192-202.

Zhang, P., Liu, J., Cheng, Y., Hou, H., Wang, C. \& Li, Y. 2015. Dynamic response of metallic trapezoidal corrugated-core sandwich panels subjected to air blast loading-An experimental study. Materials \& Design (1980-2015), 65, 221-230. 